\title{
Mitodepressive and clastogenic effects of aqueous extracts of the lichens Myelochroa lindmanii and Canoparmelia texana (Lecanorales, Parmeliaceae) on meristematic cells in plant bioassays
}

\author{
José Marcello Salabert de Campos ${ }^{1}$, Lisete Chamma Davide ${ }^{1}$, Geraldo Luiz Gonçalves Soares ${ }^{2}$ \\ and Lyderson Facio Viccini ${ }^{3}$ \\ ${ }^{1}$ Departamento de Biologia, Universidade Federal de Lavras, Lavras, MG, Brazil. \\ ${ }^{2}$ Departamento de Botânica, Universidade Federal do Rio Grande do Sul, Porto Alegre, RS, Brazil. \\ ${ }^{3}$ Departamento de Biologia, Universidade Federal University de Juiz de Fora, Juiz de Fora, MG, Brazil.
}

\begin{abstract}
The cytotoxicity effect of aqueous extracts of the lichens species Myelochroa lindmanii and Canoparmelia texana (Lecanorales, Parmeliaceae) were evaluated using meristematic cells of lettuce (Lactuca sativa) and maize (Zea mays). The seasonal effect was also evaluated. Extracts of $M$. lindmanii and $C$. texana inhibited root growth and/or percentage germination, possibly due to alterations in the cell cycle. The $M$. lindmanii extract showed anti-mitotic effects and blocked the cell cycle in metaphase so that c-mitosis and cells with chromosome duplication were produced. The $C$. texana extract appeared to hinder cell division, increasing the number of interphase cells. In addition, both extracts caused an increase in percentage of cell death. Clastogenic effects were also observed, such as sticky chromosomes, bridges, fragments and later segregation. Both lichen species are thus potential sources of biologically active substances with possible applications in biology, medicine and agronomy.
\end{abstract}

Key words: Canoparmelia texana, cytotoxicity, mitotic index, Myelochroa lindmanii, plant bioassays.

Received: April 12, 2007; Accepted: September 25, 2007.

Lichens are symbiotic organisms and together with some marine organisms and frog venom, are some of the most important sources of biologically active compounds (Barnes, 2000) with antitumour, antiviral, antimycobacterial, antiinflamatory, antiherbivoral, immunostimulating, cytotoxic and mito-depressive effects (Perry et al., 1999; Vijayakumar et al., 2000; Cochietto et al., 2002). However, few studies have been done with lichens and screening bioassays are essential tools for identifying the effects of lichens. Using plant cytogenetic tests, the effects can be observed at chromosome level (clastogenesis) through alterations in chromosome structure and number (aneuploidy, polyploidy) (Grant, 1994). A wide range of plant screening procedures are available, notable among them lettuce (Lactuca sativa L.), used in root growth and germination tests (Chon et al., 2005), and maize (Zea mays L.), commonly used as a cytotoxicity evaluation model (Pavel and Creanga, 2005).

Send correspondence to José Marcello Salabert de Campos. Universidade Federal de Lavras, Departamento de Biologia, Campus Universitário, 37200-000 Lavras, MG, Brazil. E-mail: jmscampos@ yahoo.com.br.
In recent unpublished work we observed that aqueous extracts of the lichens Myelochroa lindmanii (Lynge) Elix \& Hale and Canoparmelia texana (Tuckermann) Elix \& Hale (Lecanorales, Parmeliaceae) inhibited the root growth of $L$. sativa in an allelopathic test, an observation which led to the work described in the present paper.

Considering that little knowledge about these species is available, we designed the present study to evaluate the effects of the $M$. lindmanii and C. texana extracts on germination, root growth and chromosome alterations in lettuce and maize.

We collected $M$. lindmanii and $C$. texana twice in the rainy season (January, summer) and twice in the dry season (August, winter) in Juiz de Fora city, Minas Gerais state, Brazil $\left(-21.77^{\circ} \mathrm{S},-43.35^{\circ} \mathrm{W}\right)$. The climatological details of these seasons were obtained from the Laboratory of Climatology and Environmental Analysis at the Federal University of Juiz de Fora (UFJF) and are shown in Table 1. Voucher specimens were identified according to Ribeiro CH (MSc dissertation, UNESP, Botucatu, SP, 1998) and deposited at the Leopoldo Krieger herbarium (UFJF) as $M$. lindmanii (Voucher: 31656) and C. texana (Voucher: 31658). 
An aqueous extract was prepared from each lichen by infusing macerated lichen tissue in distilled water at a lichen-to-water ratio of 1:10 (w/v) during $24 \mathrm{~h}$ at $25^{\circ} \mathrm{C}$. The extracts were filtered through a Whatman number 1 filter paper and stored at $4{ }^{\circ} \mathrm{C}$.

To evaluate the effects of the extract on percentage germination, root growth and cytogenetic alterations we used Grand Rapids variety lettuce seeds and inbred maize line L-922 seeds (UFV).

For germination and root growth analysis we used a completely random design with 4 replicates. For each replicate, we placed 30 lettuce seeds and 30 maize seeds in separate petri dishes, added $5 \mathrm{~mL}$ of extract to each dish and incubated them at $25^{\circ} \mathrm{C}$ for $72 \mathrm{~h}$, after which we assessed the percentage germination and root growth in millimeter. Control experiments replaced the extract with the same volume of distilled water.

For cytogenetic analysis seeds were treated with distilled water as described above until root emergence and then $5 \mathrm{~mL}$ of lichen extract was added and the seeds incubated at $25{ }^{\circ} \mathrm{C}$ for $36 \mathrm{~h}$. After incubation, eight root tips ( 5 to $10 \mathrm{~mm}$ long) were collected from each dish, washed in distilled water and fixed in fresh cold 3:1 methanol:acetic acid (v/v). Slides were made by the air drying technique with enzymatic maceration (Carvalho and Saraiva, 1993) using 1:10 (v/v) Pectinex (Novo Nordisk):sodium citrate buffer, incubated at $34{ }^{\circ} \mathrm{C}$ and stained with $5 \%$ Giemsa. Mitotic and metaphase indices and the percentage of cytogenetic abnormalities (bridges, fragments, sticky chromosomes, later segregation, chromosome duplication, c-metaphase and cell death) were assessed by scoring a minimum of 500 cells from each slide, with almost 12000 cells being analyzed per treatment.

The results for each season (dry or rainy) were obtained by calculating the average of the two collections. Statistical analysis was accomplished using the Tukey test $(\mathrm{p}<0.05)$.

The $M$. lindmanii extract reduced root growth in both L. sativa and Z. mays but did not affect percentage germination, whereas the $C$. texana extracts reduced root growth in L. sativa only and percentage germination in both $L$. sativa and $Z$. mays, mainly when the lichens were collected during the rainy season (Table 2 ).

In general, inhibition of root growth and percentage germination were more evident for extracts made from ma- terial collected during rainy season. We used cytogenetic analysis to investigate the mechanisms involved in reduction of root growth and found that $M$. lindmanii extract caused an increase in mitotic index in both $Z$. mays and $L$. sativa, due to an increase of the metaphase number, whereas $C$. texana extract produced a reduction in both mitotic index and metaphase index, principally for the extracts produced from material collected in the rainy season as was observed for the M. lindmanii extract (Table 2).

The extracts of both lichens induced cytologic and chromosome alterations. In L. sativa meristematic cells treated with $M$. lindmanii extract prepared from material collected in the rainy season there was a increase of 2.4, 10.7 and 4.1 times respectively for bridges, cell death and c-metaphase (Table 2). Similar, but smaller, effects being seen with material collected in the dry season (Table 2). The effect of $M$. lindmanii extract was similar in Z. mays meristematic cells, with significant effects on c-metaphases, anaphase/telophase bridges, chromosome fragments and cell death. Some chromosome/cell abnormalities being show in Figure 1.

We also observed a large increase in the percentage of Z. mays anaphase/telophase bridges. The increase being 7 times for $M$. lindmanii extract prepared from material collected in the rainy season and 2.8 times for extract made from material collected in the dry season. In addition, some Z. mays cells with duplicated chromosome numbers were observed after treatment with $M$. lindmanii extract made from material collected in the both seasons (Figure 1).

The C. texana extract produced less intense clastogenic effects than the $M$. lindmanii extract, with only sticky chromosomes and cell death being observed in L. sativa and Z. mays meristematic cells (Table 2, Figure 1). Unlike the effect of $M$. lindmanii extracts, sticky chromosomes constitute an important consequence of the $C$. texana extract. In general, we verified that collections from the rainy season caused larger effects.

Information about the effects of lichen extracts on plant cells is still scarce considering the large number of lichen species. In this paper we have reported cytotoxic effects of lichen extracts on L. sativa and Z. mays at both the macroscopic level (percentage germination and root growth) and the microscopic level (cytogenetic analysis), with, in general, the extracts producing effects in all the tests. Macroscopically, we observed that the extracts tested

Table 1 - The climatological data during the collection of the lichens Myelochroa lindmanii and Canoparmelia texana in the city of Juiz de Fora (Minas Gerais. Data from the Laboratory of Climatology and Environmental Analysis, Federal University of Juiz de Fora, Brazil).

\begin{tabular}{|c|c|c|c|c|c|c|}
\hline & \multicolumn{3}{|c|}{ Dry season collections (winter) } & \multicolumn{3}{|c|}{ Rainy season collections (summer) } \\
\hline & First (August) & Second (August) & Mean & First (January) & Second (January) & Mean \\
\hline Temperature $\left({ }^{\circ} \mathrm{C}\right)$ & 19.8 & 15.4 & 17.6 & 22.4 & 24.0 & 23.2 \\
\hline Humidity (\%) & 65.6 & 71.8 & 68.7 & 82.1 & 78.9 & 80.5 \\
\hline Precipitation $(\mathrm{mm})$ & 0 & 0 & 0 & 77.4 & 83.6 & 80.5 \\
\hline
\end{tabular}


Table 2 - Root growth (cm), germination (\%) and cytogenetic alterations (\%) in Lactuca sativa and Zea mays treated with aqueous extracts of Myelochroa lindmanii and Canoparmelia texana collected in the city of Juiz de Fora (Minas Gerais state, Brazil) during the rainy season (January, summer) and dry season (August, winter).

\begin{tabular}{|c|c|c|c|c|c|c|}
\hline \multirow[b]{3}{*}{ Model and parameters } & \multicolumn{6}{|c|}{ Treatments } \\
\hline & \multicolumn{3}{|c|}{ Rainy season } & \multicolumn{3}{|c|}{ Dry season } \\
\hline & Control & M. lindmanii & C. texana & Control & M. lindmanii & C. texana \\
\hline \multicolumn{7}{|l|}{ L. sativa } \\
\hline Root growth $(\mathrm{cm})$ & 2.81 & $0.46^{*}$ & $0.78 *$ & 2.14 & $0.95 *$ & $1.28 *$ \\
\hline Germination & 95.25 & 91.25 & $68.75^{*}$ & 94.05 & 93.40 & $71.40^{*}$ \\
\hline Mitotic index & 3.79 & $8.15^{*}$ & $2.90 *$ & 3.81 & $5.95 *$ & $3.12 *$ \\
\hline Metaphase index & 1.12 & $4.61 *$ & $0.78 *$ & 1.35 & $2.76^{*}$ & $0.40 *$ \\
\hline Sticky & 5.11 & 6.90 & $12.75^{*}$ & 6.55 & 6.60 & $10.00 *$ \\
\hline Bridges & 0.70 & $1.65^{*}$ & 1.30 & 1.10 & $1.85^{*}$ & 1.35 \\
\hline Fragments & 0.13 & 0.13 & 0.09 & 0.06 & 0.14 & 0.07 \\
\hline Late segregation & 1.05 & 1.20 & 1.55 & 1.36 & 1.40 & 1.05 \\
\hline Cell death & 2.55 & $27.40^{*}$ & $19.60 *$ & 2.55 & $11.30 *$ & $27.15^{*}$ \\
\hline c-metaphase & 6.55 & $26.70 *$ & 8.75 & 7.65 & $10.70 *$ & 6.10 \\
\hline \multicolumn{7}{|l|}{ Z. mays } \\
\hline Root growth $(\mathrm{cm})$ & 8.00 & $4.00 *$ & 6.25 & 8.50 & $5.55^{*}$ & 6.85 \\
\hline Germination & 86.85 & 77.75 & $72.25 *$ & 80.25 & 84.85 & 80.00 \\
\hline Mitotic index & 5.95 & $7.29 *$ & $2.78^{*}$ & 6.66 & 6.71 & $2.75^{*}$ \\
\hline Metaphase index & 1.88 & $3.43^{*}$ & $0.72 *$ & 2.20 & 2.28 & $1.01 *$ \\
\hline Sticky & 2.00 & 2.20 & $3.55^{*}$ & 1.80 & 1.50 & $3.05^{*}$ \\
\hline Bridges & 0.80 & $5.65^{*}$ & 1.55 & 1.20 & $3.40 *$ & 1.20 \\
\hline Fragments & 0.15 & $1.25^{*}$ & 0.13 & 0.10 & $0.91 *$ & 0.06 \\
\hline Late segregation & 1.15 & 1.35 & 0.65 & 0.85 & 1.20 & 0.80 \\
\hline Cell death & 2.70 & $20.35 *$ & $16.65^{*}$ & 2.05 & $15.85^{*}$ & $10.60 *$ \\
\hline c-metaphase & 4.25 & $9.00 *$ & 4.95 & 3.45 & $6.45^{*}$ & 2.85 \\
\hline
\end{tabular}

*Means statistically significant in relation to the distilled water control (Tukey test, $\mathrm{p}<0.05$ ).

interfered with the percentage germination and/or root growth of both $L$. sativa and Z. mays. The effect of the extracts appeared to be directly related to interference in the cell division process, including blocking cell division and the induction of c-metaphases. The increase in mitotic index caused by M. lindmanii extract could have been due to the interruption of the cell cycle and the accumulation of metaphase stage cells. The $M$. lindmanii extract seemed to act as an antimitotic, some of which affect the dynamics of microtubules which carry out important cell functions such as chromosome migration, cell structure and cell wall formation during both growth and the mitotic cycle (Jordan and Wilson, 1999). Treatment with $M$. lindmanii extract appeared to affect the normal microtubule function, an hypothesis reinforced by the observed increase in the number of c-metaphases, increased late segregation of chromosomes and the presence of some cells with chromosome duplication. The observation of some cells with micronuclei and multipolar anaphases (data not shown) reinforces the hypothesis that this extract can act on microtubules. Verhoeven et al. (1990) demonstrated that micronuclei can start to appear in condensed metaphase chromosomes spread in c-metaphase cells. Ramulu et al. (1995) reported that when microtubules are not formed, micro-nucleation occurs as a consequence of modified mitosis in which metaphase chromosomes form the micronuclei directly without the division of centromeres and sister chromatid separation.

The $M$. lindmanii extract produced no effect on germination but it is important to note that in our study germination was considered to have occurred when the radicle emerged, and at this initial stage of germination mitosis might not have been affected. Previous studies of several species have shown that specific inhibitors of mitosis did not hinder the initial stage of germination and suggests that mitosis is not always essential for germination (Labouriau and Spillmann, 1989), indicating that germination could be controlled by metabolic mechanisms that precede cell division. Even so, in our experiments, M. lindmanii extracts produced a marked inhibition in root growth in subsequent stages of germination. The $C$. texana extracts appear to act through a different mechanism, because our experiments 


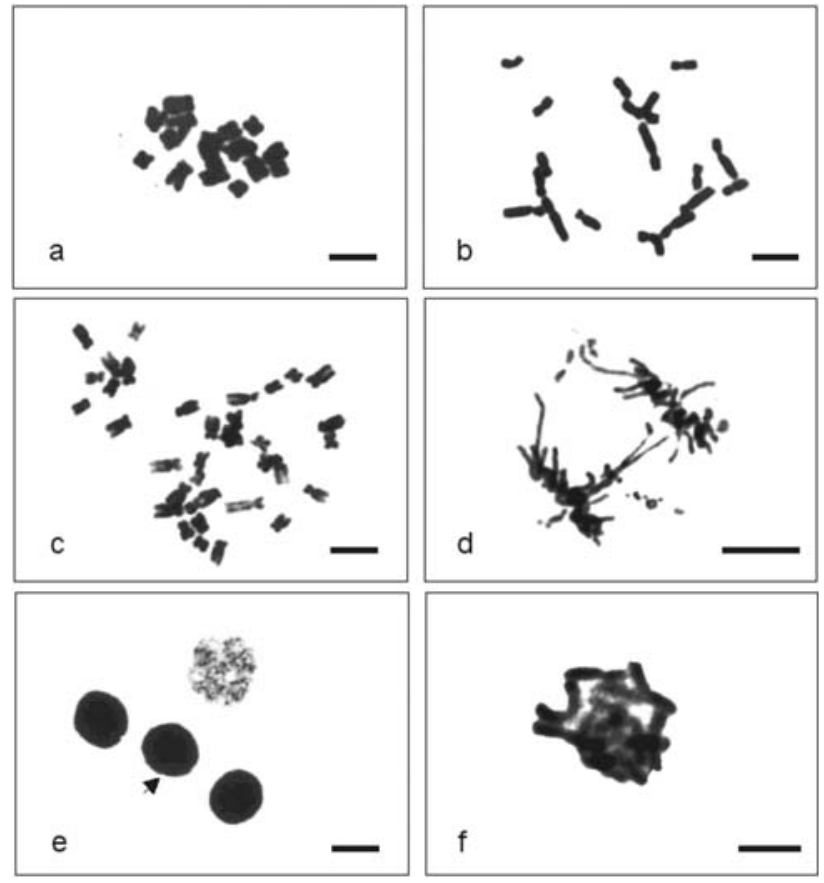

Figure 1 - Cytogenetic alterations in meristematic cells of Lactuca sativa and Zea mays. ( $\mathrm{a}$ and $\mathrm{b})$ L. sativa cells treated with $M$. lindmanii showing c-metaphase cells; (c) L. sativa cell treated with $M$. lindmanii extract showing chromosome duplication; (d) Z. mays cell treated with $M$. lindmanii extract showing bridges and fragments; (e) Z. mays cell death (arrows) after treatment with Canoparmelia texana extract; (f) Z. mays cell treated with $C$. texana extract showing sticky chromosomes. Bar $=5 \mu \mathrm{m}$.

showed that these extracts provoked a decrease in mitotic index due to an increased number of interphase or dead cells. However, the $C$. texana extracts did not seem to affect microtubule dynamics. Vyvyan (2002) has suggested that the accumulation of interphase cells may be due to inhibition of DNA synthesis.

The clastogenic effects caused by the extracts from both lichen species included anaphase/telophase bridges, chromosome fragments and sticky chromosome. Babich et al. (1997) reported that metaphases with sticky chromosomes lose their normal appearance and appear to have a sticky "surface" which causes chromosome agglomeration, possibly due to effects on chromatin and chromosome organization. Singh (2003) states that the presence of chromosome fragments is an indication of chromosome breaks, and can be a consequence of anaphase/telophase bridges. Our observations suggests that the lichen extracts not only interfered with the cell cycle but also affected chromatin organization and caused chromosome breaks.

Reigosa et al. (1999) state that, in plants, the amount and quality of allelopathic substances vary due to internal and external factors. Several studies have evaluated the seasonal effect of natural substances which can be influenced by different environmental factors, including temperature, light intensity, rainfall and the length of previous dry periods. Some studies have shown the influence of ecological factors on the concentration of secondary metabolites, with Nash and Olafsen (1995) having reported that climate change can influence the ecophysiological response of lichens.

The M. lindmanii and C. texana extracts used in our study were produced from material collected during both the dry and the rainy season so that we could investigate the effect of environmental changes. Our results indicate that, in general, the effects of $M$. lindmanii and $C$. texana extracts were intensified when using material collected during the rainy season.

Information on the biochemistry of these $M$. lindmanii and C. texana is still scarce, but the lichen paradepside atranorin is known to be a chemical taxonomic marker for these species (Ribeiro $\mathrm{CH}, \mathrm{MSc}$ dissertation, UNESP, Botucatu, SP, 1998). Marante et al. (2003) suggested that the paradepsides atranorin and chloroatranorin, could act as "parent metabolites" for the enzymatic and/or chemical transformation of a series of compounds that are released into the environment during rainy weather, when conditions favor their hydrolysis and the lichen needs to combat the germination and growth of plants. Marante et al. (2003) also describe the chemical composition and phytotoxicity and antioxidative activity of allelochemicals from the lichen Lethariella canariensis, also a member of the Parmeliaceae, and reported that a phytotoxic mixture of compounds from this lichen is leached into the environment by rainwater where they accumulate by resisting microbiological degradation and act as allelochemicals after penetrating the cell walls of seeds. Furthermore, Marante et al. (2003) present results which suggest that atranorin and chloroatranorin undergo hydrolysis to produce monocyclic fragments that are present in varying amounts in the thallus of L. canariensis and should be considered as true stress metabolites whose concentrations fluctuate with the climatic conditions. The paradepsides accumulate in the dry season, whereas in the rainy season environmental humidity increases and enhances the production of the monocyclic fragments (principally methyl- $\beta$-orsellinate, atranol and chloroatranol), with rainwater leaching the phenolic metabolites into the soil where they accumulate. The presence of atranorin in $M$. lindmanii and $C$. texana suggests a relationship between these substances and the effects observed in our study. The seasonal effects observed by us regarding the increased activity of the extracts prepared from material collected during the rainy season reinforcing this hypothesis. These are the challenges for further investigations in our laboratory, where work is underway to elucidate the relationship between the seasonal chemical composition of $M$. lindmanii and C. texana and the genetic and cellular effects described in the present paper. 


\section{Acknowledgments}

The authors thank the Brazilian Federal agency Coordenação de Aperfeiçoamento de Pessoal de Nível Superior (CAPES) for financial support and Juliana Lanna for assistance in the identification and collection of lichens.

\section{References}

Babich H, Segall MA and Fox KD (1997) The Allium test - A simple, eukaryote genotoxicity assay. Am Biol Teach 59:580583.

Barnes J (2000) Pharmacognosy in the $21^{\text {st }}$ century. Pharm J 264:701-703.

Carvalho CR and Saraiva LS (1993) A new heterochromatin banding patterns revealed by modified HKG banding technique in maize chromosomes. Heredity 70:515-519.

Chon SU, Jang HG, Kim DK, Kim YM, Boo HO and Kim YJ (2005) Allelopathic potential in lettuce (Lactuca sativa L.) plants. Sci Hortic 106:309-317.

Cocchietto M, Skert N, Nimis PL and Sava G (2002) A review on usnic acid, an interesting natural compound. Naturwissenschaften 89:137-146.

Grant WF (1994) The present status of higher plant bioassay for detection of environmental mutagens. Mutat Res 310:175185 .

Jordan MA and.Wilson L (1999) The use and action of drugs in analyzing mitosis. Method Cell Biol 61:267-295.

Labouriau LG and Spillmann FV (1989) Germination of seeds in solutions of antimitotics. An Acad Bras Cienc 61:355-371.

Marante FJT, Castellano AG, Rosas FE, Aguiar JQ, Barreira JB (2003) Identification and quantification of allelochemicals from the lichen Lethariella canariensis: Phytotoxicity and antioxidative activity. J. Chem Ecol 29:2049-2071.

Nash TH and Olafsen AG (1995) Climate change and the ecophysiological response of arctic lichens. Lichenologist 27:559565.

Pavel A and Creanga DE (2005) Chromosomal aberrations in plants under magnetic fluid influence. J Magn Magn Mater 289:469-472.

Perry NB, Benn MH, Brennan NJ, Burgess EJ, Ellis G, Galloway DJ, Lorimer SD and Tangney D (1999) Antimicrobial, Antiviral and Cytotoxic activity of New Zealand lichens. Lichenologist 31:627-636.

Ramulu KS, Dijkhuis P, Rutgers E, Blass J, Verbeek WHJ, Herhoeven HA and Colijn-Hooymans CM (1995) Microprotoplast fusion technique: a new tool for gene transfer between sexually-incongruent plant species. Euphytica 85:255-268.

Reigosa MJ, Sánches-Moreiras A and Gonzáles L (1999) Ecophysiological approach in allelopathy. Crit Rev Plant Sci 18:575-608.

Singh RJ (2003) Plant cytogenetics. CRC Press, Boca Raton, $463 \mathrm{pp}$.

Verhoeven HA, Ramulu KS and Dijkhuis PA (1990) Comparison of the effects of various spindle toxins on metaphase arrest and formation of micronuclei in cell-suspension cultures of Nicotiana plumbaginifolia. Planta 182:408-411.

Vijayakumar CS, Viswanathan S, Kannappa RM, Parvathavarthini S, Kundu AB and Sukumar E (2000) Antiinflammatory activity of (+)-usnic acid. Fitoterapia 71:564-566.

Vyvyan JR (2002) Allelochemicals as leads for new herbicides and agrochemicals. Tetrahedron 58:1631-1646.

Associate Editor: Catarina S. Takahashi 